\title{
ESTRATÉGIAS DE IMPLEMENTAÇÃO E DESENVOLVIMENTO DE FORMAÇÃO Ả DISTÂNCIA
}

\author{
Mônica Mota Tassigny \\ Professora doutora da Universidade de Fortaleza, UNIFOR, Brasil
}

\section{INTRODUÇÃO}

Numa sociedade mundial, na qual o saber ou as competências e os conhecimentos exigidos mudam rapidamente, a aprendizagem e a capacidade de aprender revelam uma importância social e econômica fundamental. Um melhor acesso à aprendizagem permanente faz-se imprescindível no desenvolvimento pessoal e profissional de cada indivíduo.

Nesta perspectiva, o ensino à distância pode ser instrumento eficaz nas demandas de educação permanente da sociedade atual, uma vez que pode facilitar a aprendizagem ao longo da vida e pode contribuir, ao mesmo tempo, na igualdade de chances de acesso à formação, sem sacrificar a qualidade do ensino.

Em efeito, a Educação à Distância (EAD), por sua flexibilidade de tempo (horários) e lugares de aprendizagem e, sobretudo, sua faculdade de fornecer resposta imediata às necessidades de formação profissional, facilita a inserção de jovens e adultos (re-inserção) no mundo do trabalho em constante mudança e evolução.

Para que se destine a tal fim, entretanto, faz-se necessário que a EAD seja introduzida, progressivamente, em diferentes tipos e graus de ensino, de forma a ser aceita pelos atores envolvidos no processo (professores, tutores e público alvo).

Neste particular, várias estratégias poderão ajudar os estabelecimentos de ensino quando o assunto é o desafio é a implementação da EAD nas universidades.

\section{SOBRE AS ESTRATÉGIAS}

A primeira consiste em adotar uma aproximação e adaptação progressiva, e sistemática, pela introdução de cursos e programas à distância na graduação e, após avaliação da eficácia ${ }^{1}$ dos tipos de EAD ofertados, adotar as experiências bem sucedidas, progressivamente, nos níveis de ensino lato e stricto sensu (gradativamente da graduação à pós-graduação)

Isto não se faz sem uma apreciação crítica e sistemática sobre a concepção dos módulos, do curso e dos programas à distância. Nesse sentido, será vital a definição de uma estratégia institucional própria na matéria e na adoção de um processo integrado de planificação: um projeto de ensino claro, no qual, a partir do envolvimento de professores de diferentes centros de ensino, planejar os passos concretos de desenvolvimentos das formas de ensino à distância a serem adotadas pela instituição de forma a serem aceitos pelos professores da instituição e pelo público visado.

\footnotetext{
${ }^{1}$ Medida urgente consiste em avaliar os cursos já ofertados, sobretudo cabe indagar sobre a eficácia destes cursos junto aos atores que já participaram de experiências de EAD na nossa instituição de ensino.
} 
Na mesma perspectiva, os estabelecimentos de ensino devem se engajar na adequação dos cursos ao público a que se destinam, através de amplas pesquisas de mercado sobre as demandas da sociedade e sobre as características particulares do público alvo.

Outra importante estratégia consiste em adotar medidas para motivar os membros do corpo docente ${ }^{2}$ a engajarem-se no desenvolvimento de programas à distância.

A introdução da EAD nas universidades em nosso Estado ainda constitui uma inovação/desafio que pressupõe um longo período de preparação e de maturação dos atores envolvidos, imprescindíveis ao desenvolvimento de competências pedagógicas e técnicas necessárias, bem como a sedimentação de processos de sensibilização sobre o real valor pedagógico da EAD.

São medidas que se referem, portanto, a clarificação dos reais benefícios profissionais que os professores e/ou tutores podem retirar desta inovação: como perspectivas de ganhos salariais, acesso às novas formas (mais amplas e coletivas) de relação professor/aluno, elaboração de novas dinâmicas de trabalho em equipe, o surgimento de novas concepções didáticas etc.

Ademais, há que se levar em conta que a concepção dos módulos, dos cursos e dos programas à distância podem demandar muito tempo. O tempo necessário à superação de problemas técnicos e os referentes às dificuldades próprias da concepção/definição didática a ser desenvolvida.

Seria pertinente a adoção de medidas com o fim de liberar tempo aos profissionais envolvidos na efetivação de programas à distância As horas empregadas no aperfeiçoamento da pedagogia a ser implementada, além das horas de preparação dos cursos devem ser contabilizadas (como horas/aula) e levadas em conta no plano de cargos e carreira dos professores. (e/ou tutores) envolvidos no processo.

Qualquer que seja o tipo de ensino a ser adotado, o planejamento e a implementação de uma formação à distância requer recursos financeiros e humanos. Desta feita, seria conveniente investimento anual no desenvolvimento de projetos pedagógicos.

Firmar parcerias (colaboração entre instituições de diferentes tipos, cooperação empresas/universidades, convênios com organizações públicas e/ou organizações não governamentais) pode ser uma solução racional e medida eficiente na diminuição dos custos da formação à distância. Esse tipo de ação poderá permitir investimentos razoáveis no desenvolvimento coerente e pertinente de ensino à distância nas universidades

Os recursos humanos ocupam também um lugar importante na eficácia e na qualidade do ensino à distância. Os diferentes papéis a serem desempenhados (autor, tutor...) devem ser regulamentados como carreira acadêmica, respeitando-se a formação e as titulações dos atores envolvidos, de forma a criar níveis como: Professor (autor ou tutor) especialista, mestre ou doutor, bem como a categoria aluno/tutor.Aqui, também, urge a criação de um sistema especial de créditos dos cursos a serem ofertados.

\section{A ESTRUTURA BÁSICA}

De maneira mais global, seria indicado à criação de uma estrutura ${ }^{3}$ de Coordenação $e$ Planejamento (grupo de trabalho formado por profissionais de diferentes áreas) na organização do ensino à

\footnotetext{
${ }^{2}$ Seria pertinente a criação de uma carreira acadêmica similar a já estabelecida na educação presencial nas universidades.
} 
distância, atuando na estruturação e na avaliação dos programas e/ou projetos pedagógicos a serem implementados.

No mesmo contexto, seria adequada a criação de um Conselho Consultivo de Ensino $e$ Aprendizagem (equipe/grupo de trabalho multidisciplinar) composto pôr pedagogos, profissionais representantes dos diferentes centros e de técnicos (especialistas em tecnologia educacional).

Essa estrutura poderá, entre outras vantagens, organizar modelos e portofólios uniformes/flexíveis de avaliação (para os diferentes centros) e atuar na criação de projetos comuns para as diferentes áreas de conhecimento (ciências humanas, tecnológicas, administrativas, jurídicas etc), bem como promover a pesquisa em EAD, otimizando os recursos humanos e financeiros aplicados.

Deve, igualmente, contribuir na estruturação de uma linha de ação clara na criação de uma estratégia eficaz na socialização (com a comunidade acadêmica e com a sociedade em geral) da imagem e da marca da EAD (linha de ação, projeto pedagógico etc) na instituição de ensino.

A estrutura básica sugerida acima poderá também motivar, em longo prazo, a criação de um Observatório de Ensino à Distância, composto de pesquisadores e profissionais ligados ao ensino e a extensão, cuja missão estaria ligada a atualização de conhecimentos em matéria de inovações tecnológicas, informações, demandas de cursos da sociedade (mundo do trabalho), produção de materiais didáticos e de formação e apoio às novas iniciativas de EAD em nossa instituição.

Por fim, a estruturação de perfis (e/ou portofólios) e competências para a EAD na instituição. Em função da formação acadêmica, da atuação e da prática profissional, os atores envolvidos na formação à distância poderão ser classificados em:

- Autor Pedagógico: analisa as necessidades de formação; determina os objetivos e o conteúdo dos cursos; determina os métodos (paradigmas ensino/aprendizagem) e os critérios e as estratégias de avaliação; concebe os dispositivos de aprendizagem (individual e coletiva)

- Técnico de Produtos e Multimídias Educativas: examina a pertinência da escolha da mídia; previne os contextos de utilização; prevê as interações homem-mídia-máquina e define o plano de avaliação da tecnologia utilizada;

- Tutor ou Formador (professor ou aluno): Gere as aprendizagens individuais; planifica os passos da aprendizagem, aconselha e orienta; ajuda a montar o percurso da formação; gere a comunicação; organiza os grupos de trabalho; analisa as interações; gere os recursos mediando a utilização e manejo de equipamentos; responde/modera as questões individuais e/ou coletivas.

\section{CONSIDERAÇÕES FINAIS}

A título de considerações finais, acreditamos que as instituições de ensino devem definir com clareza o papel do formador à distância ${ }^{4}$. O acompanhamento e a coordenação pedagógica (formada por equipe multidisciplinar) deve se desenvolver através de um trabalho colaborativo, não dispensando o apoio de uma equipe de pesquisadores na área.

\footnotetext{
${ }^{3}$ De acordo com cada curso, esta estrutura poderá ofertar cursos e serviços, também, a outros estabelecimentos de ensino, bem como
} 
$\mathrm{Na}$ mesma direção, seria imprescindível o desenvolvimento de pesquisa sistemática e constante sobre que tipo de tecnologia pode favorecer a aprendizagem coletiva, funcionando como base de apoio de uma formação à distância de qualidade.

Faz-se necessária ainda, uma definição da linha de ação da EAD (LINARD, 1995) na instituição: a intenção, a organização e a implementação das ações concretas ${ }^{5}$ devem estar claras e acessiveis, desde o início, no contexto acadêmico.

A preparação pedagógica e, mais particularmente, o desenvolvimento de competências de comunicação e de colaboração dos atores envolvidos na formação à distância, também parece -nos indispensável.

Finalmente, a concepção de um modelo de formação à distância deve, necessariamente, incluir, em sua linha de ação, investimento na pesquisa e na estruturação de cursos destinados ao desenvolvimento de competências tecnológicas dos atores envolvidos.

Neste sentido, cremos que os indicadores acima descritos constituem princípios fundamentais e pré-requisitos na implementação e no desenvolvimento de uma formação à distância de qualidade nas instituições de ensino superior.

\section{BIBLIOGRAFIA}

BARRETO, Raquel Goulard (org). Ciberespaço e formação aberta: rumo a novas práticas educacionais? Artmed, Porto Alegre, 2002.

BELLonI, Maria Luiza. Educação à Distância Autores Associados, Campinas, 1999.

LIMA, Frederico. A sociedade digital: o emprego da tecnologia na sociedade, na cultura, na educação e nas organizações. Qualitymark. Rio de Janeiro, 2000.

LINARD, M. New debates on Learning support. Journal of Computer Assisted Learning 11(4): p.239-253, 1995.

PIO, Ana Paula Nodari, Avaliação Diagnóstica do Processo de implementação do curso de Pedagogia Habilitação Magistério das séries iniciais do ensino fundamental e educação infantil na modalidade à distância. ;Error!Marcador no definido., acesso em 22/09/2004

PRETI, Oreste Apoio à aprendizagem: 0 orientador acadêmico, In: http://www.tvebrasil.com.br/salto/boletins2002/ead/eadtxt4a.htm acesso em 22/09/2004

VETOIS, Jacques.A universidade aberta e o trabalhador estudante. In: Leopoldianum. Volume XII, dez. 1985,

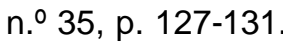

a diferentes empresas e organizações.

${ }^{4}$ Definir funções e plano de cargos e carreira acadêmica.

${ }^{5}$ A definição e o modelo de hierarquia da atividade humana proposta por Lèontiev (apud LINARD, 1995), pode se constituir em matriz teórica de estudos e pesquisas sobre os três níveis de definição de um grupo de trabalho: a intenção (a articulação entre as projeções individuais e coletivas ); a organização (a planificação do trabalho em grupo) e a ação concreta. 


\title{
Contactar
}

Revista lberoamericana de Educación

\author{
Principal OEI
}

